\title{
Uncertainty Analysis of Rear-End Collision Risk Based on Car-Following Driving Simulation Experiments
}

\author{
Qingwan Xue, ${ }^{1}$ Xuedong Yan $\mathbb{D}^{1},{ }^{1}$ Xiaomeng $L i,{ }^{2,3}$ and Yun Wang $\mathbb{D}^{1}$ \\ ${ }^{1}$ MOE Key Laboratory for Urban Transportation Complex Systems Theory and Technology, Beijing Jiaotong University, \\ Beijing 100044, China \\ ${ }^{2}$ Center for Accident Research and Road Safety-Queensland (CARRS-Q), Queensland University of Technology, \\ 130 Victoria Park Road, Kelvin Grove, Queensland 4059, Australia \\ ${ }^{3}$ Institute of Health and Biomedical Innovation (IHBI), Queensland University of Technology, 60 Musk Avenue, \\ Kelvin Grove 4059, Australia
}

Correspondence should be addressed to Xuedong Yan; xdyan@bjtu.edu.cn

Received 26 April 2018; Revised 22 May 2018; Accepted 4 September 2018; Published 20 September 2018

Academic Editor: Giancarlo Consolo

Copyright (C) 2018 Qingwan Xue et al. This is an open access article distributed under the Creative Commons Attribution License, which permits unrestricted use, distribution, and reproduction in any medium, provided the original work is properly cited.

\begin{abstract}
Rear-end collisions are one of the most common types of accidents, and the importance of examining rear-end collisions has been demonstrated by numerous accidents analysis researches. Over the past decades, lots of models have been built to describe driving behaviour during car following to better understand the cause of collisions. However, it is necessary to consider individual difference in car-following modelling while it seems to be ignored in most of previous models. In this study, a rear-end collision avoidance behaviour model considering drivers' individual differences was developed based on a common deceleration pattern extracted from driving behaviour data, which were collected in a car-following driving simulation experiment. Parameters of variables in the model were calibrated by liner regression and Monte Carlo method was adopted in model simulation for uncertainty analysis. Simulation results confirmed the effectiveness of this model by comparing them to the experiment data and the influence of driving speed and headway distance on the rear-end collision risk was indicated as well. The thresholds for driving speed and headway distance were $18 \mathrm{~m} / \mathrm{s}$ and $15 \mathrm{~m}$, respectively. An obvious increase of collision risk was observed according to the simulation results.
\end{abstract}

\section{Introduction}

According to statistics of the World Health Organization [1], road traffic injuries are one of the eight lead causes of death globally. Among all the accidents types, rear-end crashes are the most frequently occurring one, accounting for $29 \%$ approximately and resulting in a substantial number of injuries and fatalities each year [2]. The reasons which contribute to the occurrence of a rear-end accident may involve any elements that constitute the whole traffic system, such as drivers, vehicles, and road environments. Among the elements, human factor is the most influential one, to which more than $90 \%$ of the accidents are related [3]. Human factor penetrates each link of the collision event from the emergence of risk to the collision avoidance. Any small deviation in the choice of driving state, risk perception, or decision-making may lead to the occurrence of an accident.
A rear-end collision is commonly induced by the sudden deceleration of the lead vehicle during a car-following process. From traffic engineering perspective, numerous models in the previous studies have been developed to describe carfollowing behaviour, including the Gazis-Herman-Rothery (GHR) model, the safety distance model, and the optimal velocity model $[4,5]$. The GHR model assumed that drivers take an acceleration or deceleration action according to the speed relative to the lead vehicle and has been widely adopted due to its simplicity [6]. The safety distance model was first proposed by Kometani and Sasaki [7]. It differed from the GHR model by assuming that the drivers react to the distance relative to the lead vehicle rather than speed. The most popular safety distance model was developed by Gipps [8], which hypothesized that drivers keep safe distance so that they can stop to avoid collision with the suddenly braked lead vehicle. In this model, a constant reaction time was used 
for all vehicles. In the optimal velocity model introduced by Bando et al. [9], the vehicle was assumed to have an optimal velocity, which depended on the distance from the lead vehicle. Sun [10] proposed an extended heterogeneous carfollowing model by considering relative velocity and mixed maximum speeds into optimal velocity function. Yu and Shi $[11,12]$ further extended the model with driver memory and found that the stability of traffic flow could be improved by considering memory effect in car-following behaviour. Later, the generalized force model [13], relative velocity difference model $[14,15]$, and full velocity difference model $[16,17]$ were developed on the base of optimal velocity model.

However, the prior engineering car-following models tend to focus on the physical behaviour while ignoring the drivers' subjective role in accomplishing the driving task. The subsequent car-following models incorporating with human factors and environmental factors were then proposed. In the action point model firstly developed by Michaels [18], drivers perceived relative velocity according to the changes on the visual angle subtended by the lead vehicle. When the perception threshold was exceeded, drivers would brake until they can no longer perceive any relative velocity. The relative distance and speed which were used in several engineering car-following models were replaced by visual angle and angular velocity in this model [19]. Both Zhou [20] and Hou [21] proposed extended car-following models by introducing the driver's visual angle into the full velocity difference model and found the proposed models were able to explain some complex nature of traffic phenomena. Nevertheless, the driver's reaction time was ignored in the action point model and a constant desired visual angle was used for simulation. In the further research, this model has been applied in many studies, but it seems challenging to select an appropriate visual angle [22-24].

For the diverse car-following models mentioned above, the common limitation was that drivers' individual difference in different situations was not truly reflected. In most of the models, drivers' reaction time was set to be identical for all drivers or even neglected. Even for the action point model, the human factor was limited to drivers' perception of the relative velocity. However, as Hamdar [25] and Treiber and Kesting [26] presented, the human factors such as perception threshold and spatial anticipation can be quite different from individuals. Due to the variance of human behaviour and management decisions, the uncertainty analysis was then introduced to the transportation area. Sheu and $\mathrm{Wu}$ [27] proposed a dynamic driving perception model to investigate the relationship of perception uncertainty with reaction time in car following from a quantum optical flow perspective. Kim et al. [28] investigated the uncertainty of drivers' response to stimuli in car following with a random coefficient model. Among the research by utilizing uncertainty analysis, Monte Carlo is one of the commonly used methods [29-32]. It has been widely used in systemic accident risk assessment in air traffic [33-35] while the utilization in car following is very rare.

However, the uncertainty of human factors also brings difficulties in collecting data. The traditional data used in carfollowing model are generally collected by loop detectors that can only provide the vehicle information while human factors are often simplified. However, the emergence of driving simulator provides an efficient method to deal with data collection problems. More importantly, the driving simulator tests can be conducted in controlled and high-risk conditions, e.g., potential rear-end collision, while the safety of participants can be ensured which was impossible in real traffic situation presently. Previous studies have shown that driving simulator is a reliable and valid apparatus to examine drivers' behaviour [36-38]. Muhrer and Vollrath [39] examined drivers' carfollowing behaviour by varying the lead vehicle's driving status (different braking behaviour, signaling or not before a turn) in a driving simulator experiment. Results indicated that drivers who do not foresee the sudden brake of the lead vehicle always cannot react in time. Based on a driving simulator experiment, Bella et al. [40] analyzed the driving behaviour during a car-following situation and developed a new collision warning algorithm which can reflect the real risk perception by drivers.

In the present study, a high-fidelity driving simulator was used to investigate drivers' car-following behaviour and rearend collision avoidance performance. A rear-end collision risk analysis approach was proposed with consideration of uncertainty existing in the key variables, e.g., drivers' reaction time, deceleration control time, and maximum deceleration rate. The model can be used to quantify the collision risk associated with parameters in the form of normal distribution instead of constant value. As the car-following behaviour maneuver may influence the potential rear-end collision risk undertaken, the relationship between driving speed, headway distance, and collision risk was then analyzed and discussed based on the Monte Carlo simulation results.

\section{Methods}

2.1. Research Framework. The study focused on investigating drivers' rear-end avoidance performance during a carfollowing process and examining the rear-end collision risk distribution considering drivers' uncertainty. Figure 1 shows the basic research framework of this paper. First, a carfollowing experiment was conducted in a driving simulator to collect driving behaviour data related to the potential rear-end collision risk. In this experiment, scenarios with bidirectional single straight lanes were established while the lead vehicle in each scenario was driving at different initial speeds. The experiment results were used to extract drivers' common deceleration pattern when reacting to the lead vehicle's deceleration. Based on the pattern, a rear-end collision avoidance behaviour model was then developed and calibrated by linear regression based on driving behaviour variables such as reaction time, decelerating control time, and drivers' maximum deceleration rate. Considering the uncertainty of driving behaviour variables in form of normal distribution, the Monte Carlo simulation was further applied to quantify the rear-end crash risk. The uncertainty analyses can display the relationship between the probability of rearend collision and the car-following behaviour parameters, i.e., reaction time, headway distance, and driving speed. 


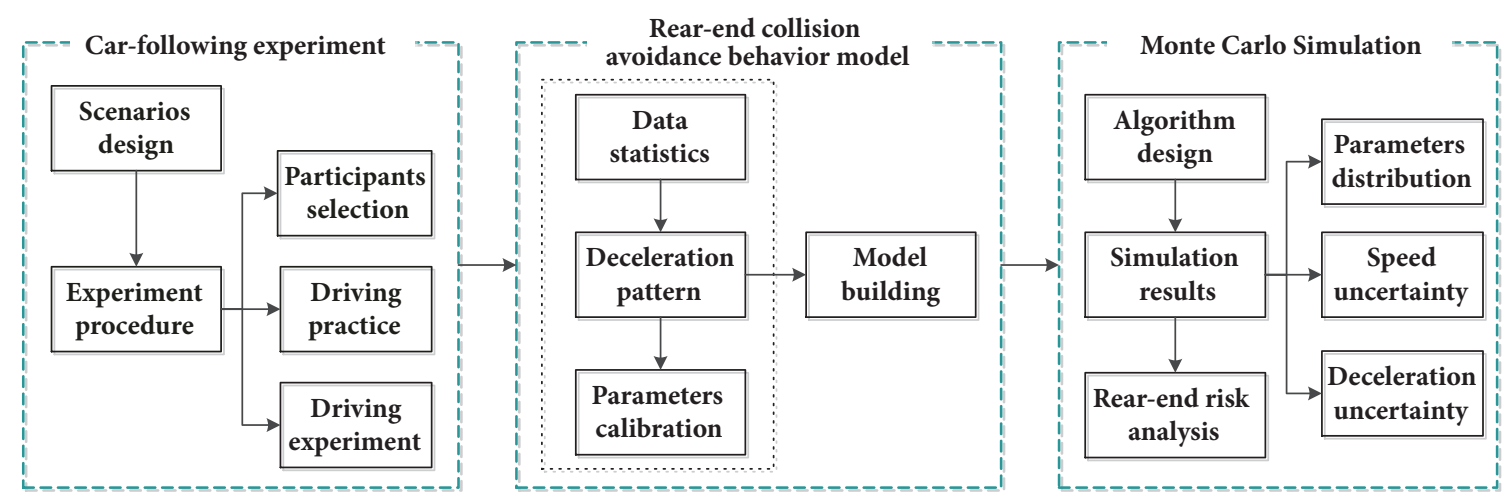

FIGURE 1: Research framework of this paper.

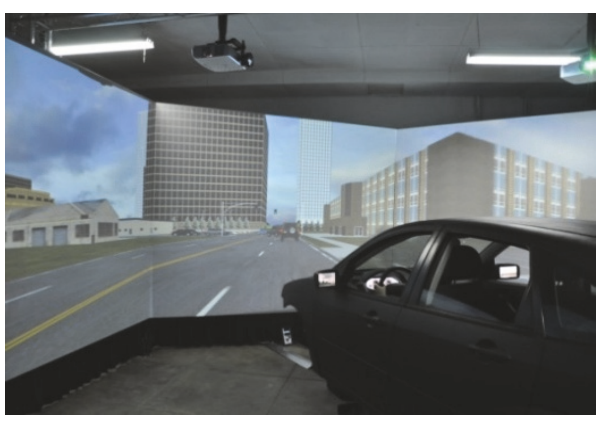

(a)

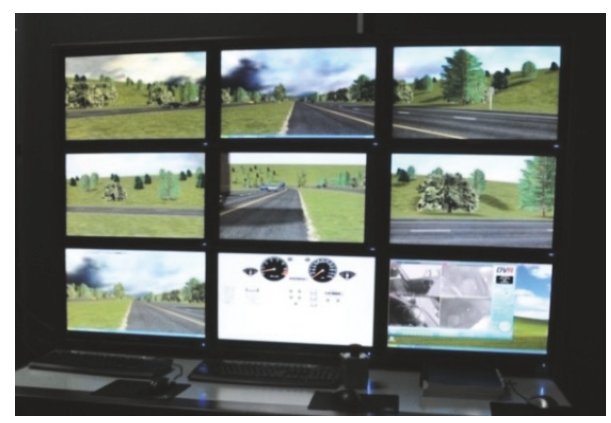

(b)

FIGURE 2: Illustration of the driving simulator system: (a) realistic cabin of Ford Focus and (b) operation system.

\subsection{Data Collection Based on Driving Simulation Experiment}

2.2.1. Subjects. In this experiment, a total of 46 participants (24 males vs. 22 females) were recruited. Each participant held a valid Chinese driver license and had at least oneyear driving experience and 30,000 km driving mileage. After arrival, each participant was briefed on the requirements of the experiment and all signed informed consent form. Before the formal experiment, the participants were given at least 10 min of training to familiarize them with the driving simulator operation. When the formal experiment began, the participants would rest for at least $5 \mathrm{~min}$ between the tests. All participants would receive 100 RMB (around 15 USD) for their attendance.

2.2.2. Equipment. The equipment used in this experiment is Beijing Jiaotong University driving simulator (as shown in Figure 2). The simulator is composed of a realistic cabin of Ford Focus and automatic gearbox, gas/brake pedal, and other components which are in full accordance with the real vehicle. The driving scenarios are designed with special software and projected on five screens with a resolution of $1400 \times 1050$ pixels to realize a driver's 300 -degree field of frontview and three rear-view mirrors (left, middle, and right), which are simulated by LCD screens. The simulated vibration system, environmental noise system, and one-degree-offreedom motion platform ensure that drivers in the simulator can react just as in real traffic conditions.
2.2.3. Scenario Design. In this study, scenarios with a bidirectional two-way straight segment with the speed limit of $60 \mathrm{~km} / \mathrm{h}$ were created. Three kinds of initial driving speeds $(60 \mathrm{~km} / \mathrm{h}, 40 \mathrm{~km} / \mathrm{h}$, and $20 \mathrm{~km} / \mathrm{h})$ of the lead vehicle were designed in this experiment, corresponding to three levels of traffic congestion. Within each level of traffic congestion scenarios, the participants were assigned to follow a lead vehicle that was running at one of three initial speeds (as shown in Figure 3). Three sensors were designed in each scenario to trigger the lead vehicle to decelerate at an assigned deceleration rate. When the driving speed of the lead vehicle reached the designed value, the lead vehicle would drive with this constant speed until it reached the next sensor; Figure 4 shows the speed and deceleration rate of the lead vehicle. Free traffic flow was not designed in the driving lane to avoid interference with the simulator, and a series of vehicles coming from the opposite direction were arranged to simulate the realistic traffic situation and avoid the simulator's overtaking behaviour. The duration of driving one trial was about $5 \mathrm{~min}$; participants would rest for at least $5 \mathrm{~min}$ between each trial.

2.3. Rear-End Collision Avoidance Behaviour Model Development Based on Deceleration Pattern. In this study, a rearend collision avoidance behaviour model was built to analyze the collision risk induced by different collision avoidance behaviour performance considering drivers' uncertainty. Generally in an emergent collision scenario, most drivers 


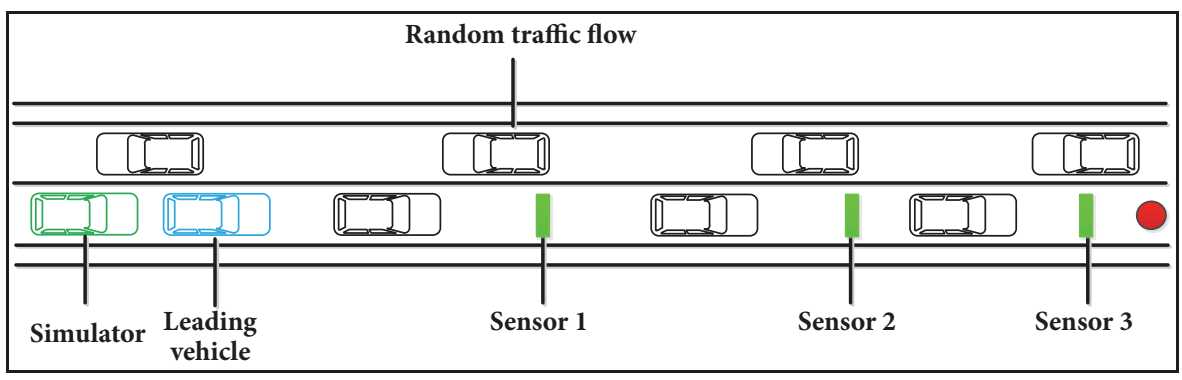

Figure 3: Car-following scenario.

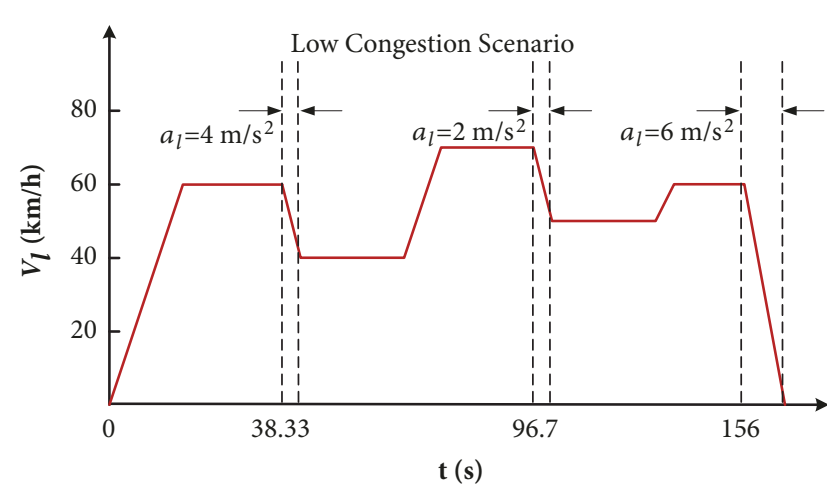

(a)

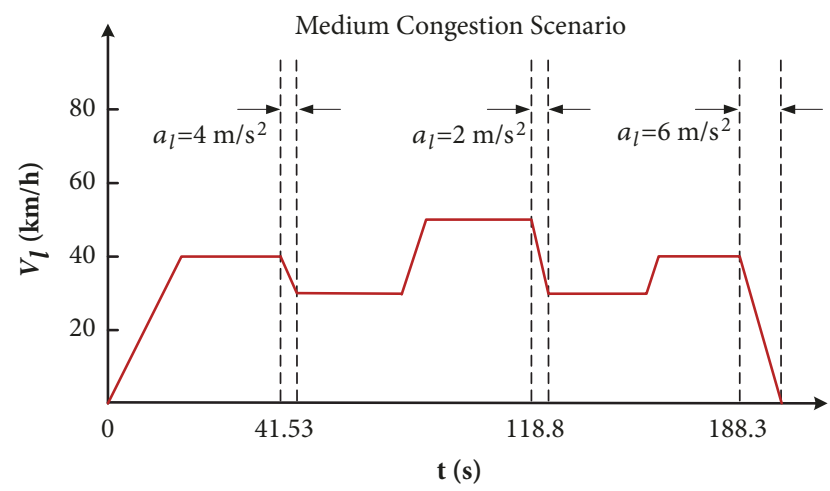

(b)

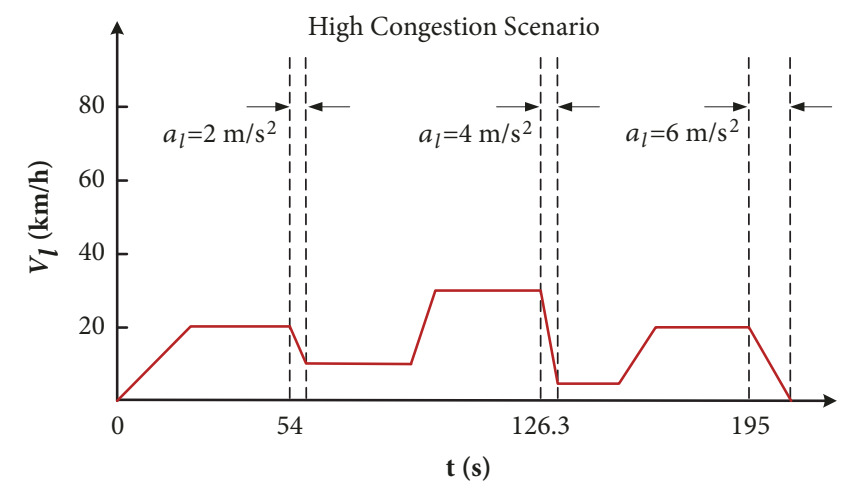

(c)

Figure 4: Speed and deceleration rate of the lead vehicle in low congestion scenario (a), medium congestion scenario (b), and high congestion scenario (c), respectively.

would take deceleration maneuver as the headmost reaction to avoid collision; others would resort to turning the steering wheel or the combination of deceleration and steering according to different collision type. Figure 5 shows the deceleration and headway distance from the brake onset of the lead vehicle to the end of the driver's brake in selected near-crashes. A common pattern can be found in the figure that, after a short reaction time, all the drivers took deceleration actions to respond to the sudden brake of the lead vehicle. In addition, the deceleration rate of drivers kept increasing until a maximum value was reached; the maximum deceleration rate stayed constant for a while and then the deceleration rate decreased to zero, meaning that the drivers recovered their speeds gradually. The pattern found here was consistent with Li et al's [41] study. The headway distance during this process continued to decrease until the following vehicle was done with its deceleration maneuver. A minimum headway distance was reached, and a rear-end collision occurred with the minimum headway distance less than a critical headway (represented as $D_{c}$ ). Because the minimum headway distance mostly occurred when drivers kept the maximum deceleration rate, the rear-end collision avoidance process in this paper was simplified into three phases including braking reaction phase $\left(0 \sim t_{r}\right)$, decelerating control phase $\left(t_{r} \sim t_{r}+t_{1}\right)$, and maximum deceleration rate keeping phase $\left(t_{r}+t_{1} \sim t_{r}+t_{1}+t_{2}\right)$, as shown in Figure 6. The definitions of the three phases are listed as follows:

(1) Braking reaction phase: the period started from deceleration of the lead vehicle to the deceleration of 

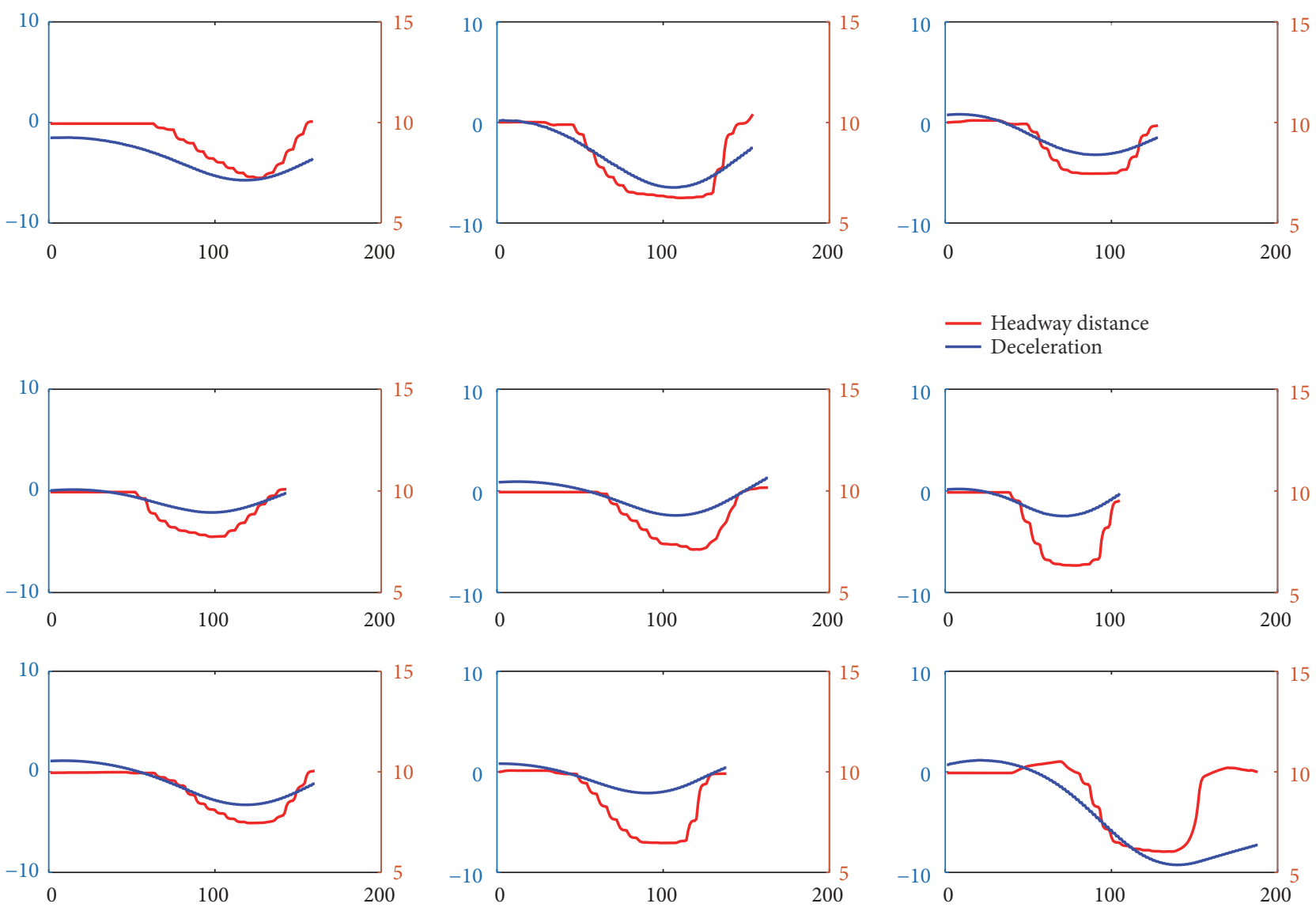

FIGURE 5: Deceleration and headway distance from the lead vehicle's brake onset to the end of the following vehicle's brake of selected nearcrashes.

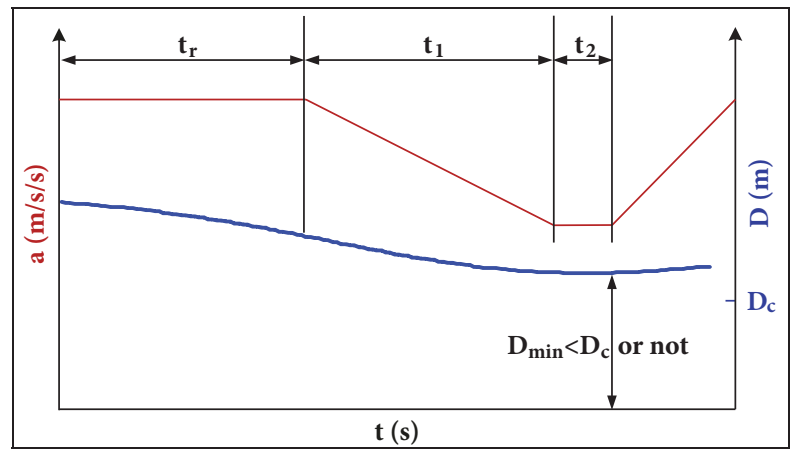

Figure 6: Three simplified phases in the rear-end collision avoidance process.

the following vehicle (simulator) and this duration is represented by $t_{r}$

(2) Decelerating control phase: during this period, the deceleration rate of the following vehicle increased to its maximum value within a time span of $t_{1}$

(3) Maximum deceleration rate keeping phase: the maximum deceleration rate of the following vehicle is kept in this phase and the time span was represented by $t_{2}$
Based on the deceleration pattern and the three phases described in Figure 6, the rear-end avoidance behaviour model was presented as follows:

$$
\begin{aligned}
& D_{\min }<D_{c}, \\
& \mathrm{D}(\mathrm{t})=D_{s}+\int_{0}^{t} V_{L}(t)-V_{F}(t) d t, \\
& a_{F}(t)= \begin{cases}0, & t \in\left(0, t_{r}\right) \\
a_{m}\left(\frac{t-t_{r}}{t_{1}}\right), & t \in\left(t_{r}, t_{r}+t_{1}\right) \\
a_{m}, & t \in\left(t_{r}+t_{1}, t_{r}+t_{1}+t_{2}\right),\end{cases} \\
& V_{L}(t)= \begin{cases}V_{L s}-a_{L} t, & t \in\left(0, t_{d}\right) \\
V_{L s}, & t \in\left(t_{d}, t_{r}+t_{1}+t_{2}\right),\end{cases} \\
& V_{F}(t) \quad t \in\left(0, t_{r}\right) \\
& = \begin{cases}V_{F S}, & t \in\left(t_{r}, t_{r}+t_{1}\right) \\
V_{F S}-a_{m} \frac{\left(t-t_{r}\right)^{2}}{2 t_{1}}, & \\
V_{F s}-\frac{a_{m} t_{1}}{2}-a_{m}\left(t-t_{r}-t_{1}\right), & t \in\left(t_{r}+t_{1}, t_{r}+t_{1}+t_{2}\right),\end{cases} \\
& t_{d}=\frac{V_{L s}-V_{L E},}{a_{L}}, \quad
\end{aligned}
$$




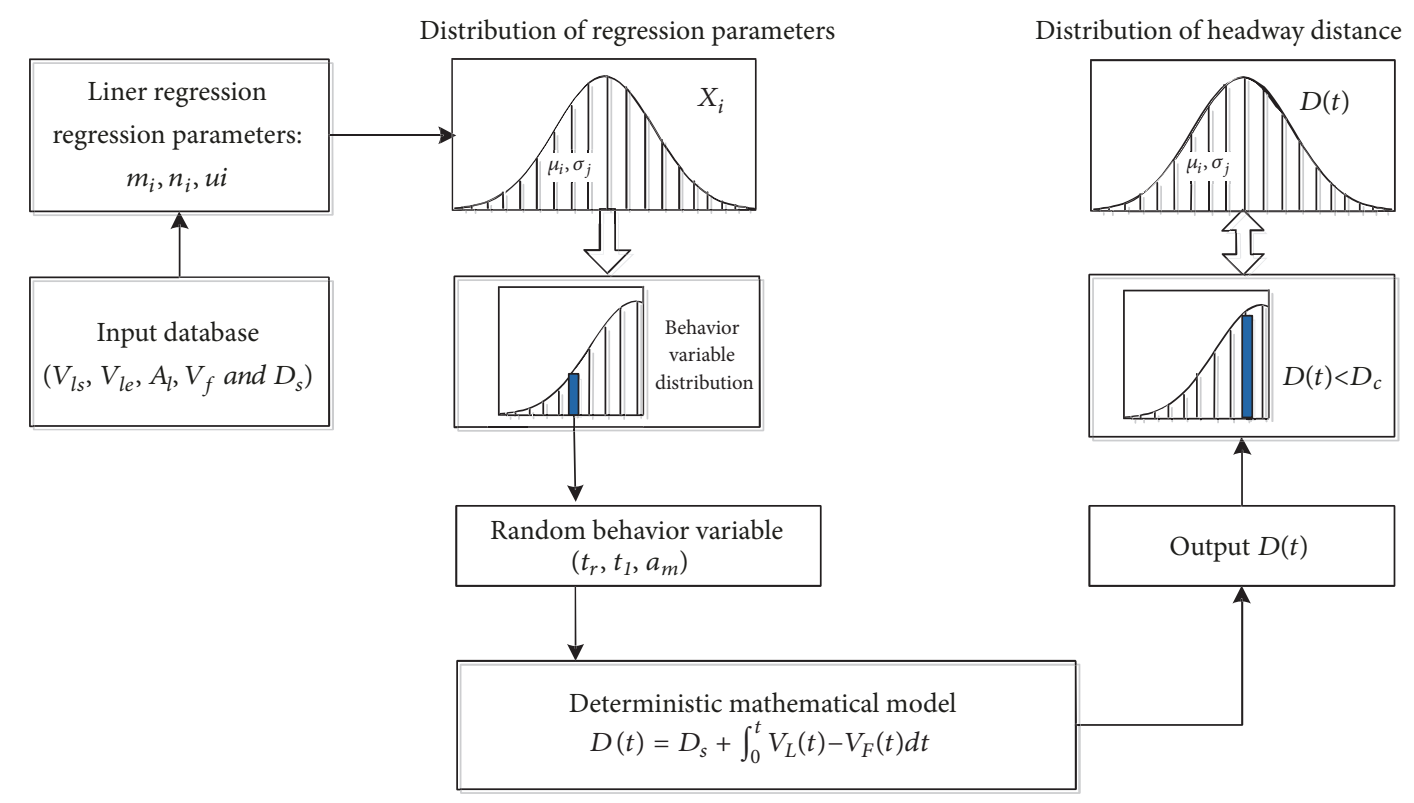

FIGURE 7: General schematic of rear-end collision risk simulation.

in which,

$D_{\text {min }}$ is minimum headway distance during rear-end collision avoidance;

$D_{c}$ is critical headway distance for rear-end collision;

$D(t)$ is headway distance during rear-end collision avoidance;

$D_{s}$ is headway distance when lead vehicle began to decelerate;

$t_{r}$ is driver's braking reaction time;

$t_{1}$ is time duration of decelerating control phase;

$t_{2}$ is time duration of maximum deceleration rate keeping phase;

$t_{d}$ is time duration of lead vehicle' deceleration;

$a_{F}(t)$ is driver's deceleration at time $t$;

$a_{m}$ is driver's maximum deceleration during the braking process;

$a_{L}$ is deceleration of lead vehicle;

$V_{L}(t)$ is speed of lead vehicle at time t;

$V_{L S}$ is initial speed of lead vehicle;

$V_{L E}$ is speed of lead vehicle after its deceleration;

$V_{F S}$ is driver's initial speed;

$V_{F}(t)$ is driver's speed at time t.

2.4. Rear-End Risk Uncertainty Analysis Based on Monte Carlo Simulation. The Monte Carlo simulation which has been widely adopted in physical process related fields [42] and economic risk analysis [43-45] is adopted in this study. The Monte Carlo simulation uses random numbers to select random samples of the required model input data with given probability density functions and operates numerous simulation replications in order to generate values for model output variables. This repetition procedure finally leads to a distribution of output variables value and usually is in the shape similar to normal distribution [46], which can be analyzed and transformed into probability density functions [42].

During the whole car following process of this experiment, driving behaviour of each driver will be uncertain and random in part due to the variety of participants. Thus, uncertainty analysis using the Monte Carlo simulation to investigate the uncertainty of several driving behaviour was applied to obtain a meaningful prediction of the probability of the collision events. In this paper, the data obtained through the driving simulator experiment was analyzed in detail to obtain input data for the Monte Carlo simulation. The parameters used to calibrate related behaviour variables were varied in the form of normal distribution, and the Monte Carlo simulation input variables were selected in the range of normal distribution at random. The criterion for the assessment of collision occurrence was evaluated by the headway distance between the lead vehicle and driving simulator. The headway distance can be calculated by the rear-end avoidance behaviour model proposed in Section 2.3. Once the headway distance was less than the critical distance, one collision occurred and counted. The simulation was run 10000 times in total. Figure 7 shows the overall Monte Carlo simulation process.

\section{Experiment Results Analysis}

3.1. Car-Following Behaviour Analysis. In the car-following process, a safety distance with the lead vehicle, a quick reaction time, and a proper speed response are undoubtedly crucial for drivers when encountered with an emergent 
TABLE 1: Results of correlation analysis.

\begin{tabular}{|c|c|c|c|c|c|}
\hline \multirow{2}{*}{ Dependent variable } & \multicolumn{5}{|c|}{ Independent Variable } \\
\hline & $a_{L}$ & $V_{L S}$ & $V_{L E}$ & $V_{F S}$ & $D_{s}$ \\
\hline$t_{r}$ & $-0.233 * *$ & $0.114 *$ & $0.155 * *$ & 0.087 & $0.373 * *$ \\
\hline$t_{1}$ & $0.186 * *$ & $0.338 * *$ & -0.078 & $0.338 * *$ & $0.360 * *$ \\
\hline$a_{m}$ & $0.501 * *$ & 0.037 & $-0.410 * *$ & 0.025 & $-0.328 * *$ \\
\hline
\end{tabular}

$* *$ Significant at the 0.01 level. $*$ Significant at the 0.05 level.

rear-end collision. According to the rear-end collision risk model proposed in Section 2.3, drivers' reaction time, maximum deceleration rates, and deceleration control time all affect the risk of rear-end collisions. However, these variables are uncertain and could be affected by the change of the lead vehicle's driving status. Therefore, some variables which can represent the lead vehicle and following vehicle's initial driving status were then extracted. Table 1 shows the correlation analysis results. It was shown that the lead vehicle's deceleration rate $a_{L}$, initial driving speed $V_{L S}$, and speed after its deceleration $V_{L E}$ all had a significant relationship with drivers' reaction time $t_{r}$. When the lead vehicle brakes harder, drivers tend to react faster with the correlation coefficient being -0.233 . The lead vehicle's driving speed before and after its deceleration also had a relationship with drivers' reaction time, but the correlation seems to be in a small magnitude with the correlation coefficient being 0.114 and 0.155 , respectively. Among the independent variables listed in Table 1, the relationship between headway distance and drivers' reaction time is the largest (correlation coefficient $=$ 0.373 ). Generally, a short headway indicates potential danger as the small available space-time is left for drivers [47]. Thus, drivers may stay alert and react fast to the speed change of the vehicle which is not far in front.

As to deceleration control time $t_{1}$, all variables had a significant correlation with it except for the lead vehicle's driving speed after deceleration. The correlation coefficients between $t_{1}$ and $V_{L S}, V_{F S}$ are both 0.338 , which indicates that when the lead vehicle brakes suddenly and the lead and following vehicles maintain a higher driving speed, drivers need a longer deceleration control time to decelerate to a certain speed. In addition, the deceleration control time also had a positive relationship with the lead vehicle's deceleration rate (correlation coefficient $=0.186$ ). When the driving condition occurred more urgently, the emergency control time for drivers tended to be longer. Headway distance is also an important variable positively correlated with emergency control time (correlation coefficient $=0.360$ ).

Intuitively, when the lead vehicle decelerates at a larger deceleration rate, the following vehicle needs to brake harder to avoid a rear-end collision accordingly. The experiment results show that the lead vehicle's deceleration rate has the strongest correlation with the following vehicle's maximum deceleration rate $a_{m}$ (correlation coefficient $=0.501$ ), whereas the lead vehicle's driving speed after deceleration $V_{L E}$ and headway distance $D_{s}$ have a negative correlation with the following vehicle's maximum deceleration rate. When the lead vehicle's driving speed does not change a lot, a smaller deceleration rate may be enough for drivers to adjust the driving speed. The larger headway distance allows a larger space-time for drivers to control the vehicle, and thus the maximum deceleration rate would be smaller.

\subsection{Development of the Rear-End Collision Avoidance} Behaviour Model. Based on the above correlation analyses, all of the variables had significant relationships with drivers' rear-end collision avoidance performance and may further affect the occurrence of rear-end crashes. Nevertheless in most previous studies, some variables indicating driver characteristics such as reaction time were usually assumed as constant across individuals (the GHR model, for example). Thus the rear-end collision avoidance behaviour model built in this study represents the collision avoidance process and contains all potential factors that can reflect the drivers' heterogeneity. Further, the linear regression analyses were conducted to model the relationships between the dependent variable $y$ and one or more explanatory variables denoted by $X_{i}$. The basic form of the model is shown as follows:

$$
y_{i}=\beta_{0}+\beta_{1} x_{i 1}+\cdots+\beta_{p} x_{i p}+\varepsilon_{i}, \quad i=1, \cdots, n .
$$

The stepwise regression as an extension of linear regression models based on Pearson's correlation coefficient was adopted in this study. In this method, a model that contains all potential dependent variables is firstly constructed, and in order to maintain the model with the highest determination coefficients and maintain the significance of the parameters, some of the variables will be then gradually eliminated [48]. Thus, the variables that can reflect the initial status of the lead vehicle and following vehicle were input as potential factors in the regression analysis to calibrate the key variables in the rear-end avoidance behaviour model, including reaction time $\left(t_{r}\right)$, decelerating control time $\left(t_{1}\right)$, and maximum deceleration $\left(a_{m}\right)$. The basic function can be described as follows and the summary of stepwise regression results of $t_{r}$, $t_{1}$, and $a_{m}$ is listed in Table 2 .

$$
\begin{aligned}
t_{r} & =m_{1} a_{L}+m_{2} V_{L s}+m_{3} V_{L E}+m_{4} V_{F S}+m_{5} D_{s}+m_{6}, \\
t_{1} & =n_{1} a_{L}+n_{2} V_{L s}+n_{3} V_{L E}+n_{4} V_{F S}+n_{5} D_{s}+n_{6}, \\
a_{m} & =u_{1} a_{L}+u_{2} V_{L s}+u_{3} V_{L E}+u_{4} V_{F S}+u_{5} D_{s}+u_{6},
\end{aligned}
$$

where $m_{i}, n_{i}$, and $u_{i}$ are regression parameters.

Thus, the regression formulas with calibrated parameters for each variable are shown as follows:

$$
t_{r}=-0.061 a_{L}-0.034 V_{F S}+0.023 D_{s}+1.327,
$$


TABLE 2: Regression results of $t_{r}, t_{1}$, and $a_{m}$.

\begin{tabular}{cccccc}
\hline Variables & Factors & $\mathrm{B}$ & $\mathrm{S} . \mathrm{D}$. & $\mathrm{t}$ & Sig. \\
\hline \multirow{4}{*}{$t_{r}$} & Constant & 1.327 & 0.090 & 13.876 & .000 \\
& $a_{L}$ & -0.061 & 0.014 & -4.476 & .000 \\
& $V_{F S}$ & -0.034 & 0.005 & -6.517 & .000 \\
& $D_{S}$ & 0.023 & 0.002 & 9.988 & .000 \\
$t_{1}$ & Constant & 0.451 & 0.081 & 5.599 & .000 \\
& $V_{L S}$ & 0.071 & 0.008 & 9.377 & .000 \\
& $V_{L E}$ & -0.070 & 0.007 & -10.281 & .000 \\
& $D_{S}$ & 0.017 & 0.003 & 6.094 & .000 \\
& Constant & 3.636 & 0.318 & 11.452 & .000 \\
$a_{m}$ & $a_{L}$ & 0.244 & 0.065 & 3.779 & .000 \\
& $V_{L S}$ & 0.212 & 0.052 & 4.080 & .000 \\
& $V_{L E}$ & -0.216 & 0.027 & -8.002 & .000 \\
& $V_{F S}$ & 0.098 & 0.049 & 1.988 & .046 \\
& $D_{S}$ & -0.094 & 0.007 & -12.546 & .000 \\
\hline
\end{tabular}

$$
\begin{aligned}
t_{1}= & 0.071 V_{L s}-0.070 V_{L E}+0.017 D_{s}+0.451, \\
a_{m}= & 0.244 a_{L}+0.212 V_{L s}-0.216 V_{L E}+0.098 V_{F S} \\
& -0.094 D_{s}+3.636 .
\end{aligned}
$$

The maximum deceleration rate keeping phase which was represented by $t_{2}$ can be calculated as the time when minimum headway distance is reached (represented by $t\left(D_{\min }\right)$ ) minus $t_{r}$ and $t_{1}$, according to the simplified deceleration rate curve shown in Figure 6. Thus, the whole rear-end collision avoidance behaviour model during deceleration process can be described as

$$
\begin{aligned}
& D_{\min }<D_{c} \text {, } \\
& \mathrm{D}(\mathrm{t})=D_{s}+\int_{0}^{t} V_{L}(t)-V_{F}(t) d t, \\
& a_{F}(t)= \begin{cases}0, & t \in\left(0, t_{r}\right) \\
a_{m}\left(\frac{t-t_{r}}{t_{1}}\right), & t \in\left(t_{r}, t_{r}+t_{1}\right) \\
a_{m}, & t \in\left(t_{r}+t_{1}, t_{r}+t_{1}+t_{2}\right),\end{cases} \\
& V_{L}(t)= \begin{cases}V_{L s}-a_{L} t, & t \in\left(0, t_{d}\right) \\
V_{L s}, & t \in\left(t_{d}, t_{r}+t_{1}+t_{2}\right),\end{cases} \\
& V_{F}(t) \\
& = \begin{cases}V_{F S}, & t \in\left(0, t_{r}\right) \\
V_{F S}-a_{m} \frac{\left(t-t_{r}\right)^{2}}{2 t_{1}}, & t \in\left(t_{r}, t_{r}+t_{1}\right) \\
V_{F S}-\frac{a_{m} t_{1}}{2}-a_{m}\left(t-t_{r}-t_{1}\right), & t \in\left(t_{r}+t_{1}, t_{r}+t_{1}+t_{2}\right),\end{cases} \\
& t_{r}=-0.061 a_{L}-0.034 V_{F S}+0.023 D_{s}+1.327 \text {, } \\
& t_{1}=0.071 V_{L s}-0.070 V_{L E}+0.017 D_{s}+0.451,
\end{aligned}
$$

$$
\begin{aligned}
& \begin{aligned}
a_{m} & \\
= & 0.244 a_{L}+0.212 V_{L s}-0.216 V_{L E}+0.098 V_{F S}-0.094 D_{s} \\
& +3.636
\end{aligned} \\
& t_{2}=t\left(D_{\min }\right)-t_{r}-t_{1} \\
& t_{d}=\frac{V_{L s}-V_{L E}}{a_{L}} .
\end{aligned}
$$

3.3. Uncertainty Analysis of Rear-End Risk. The rear-end collision avoidance behaviour model was further applied for the Monte Carlo simulation. In the simulation, the lead vehicle was assumed to decelerate from $60 \mathrm{~km} / \mathrm{h}$ to 40 $\mathrm{km} / \mathrm{h}$ with a deceleration rate of $4 \mathrm{~m} / \mathrm{s}^{2}$. The distributions of regression parameters with a $95 \%$ of confidence interval for determining $t_{r}, t_{1}$, and $a_{m}$ are listed in Table 3 . The initial speed $\left(V_{F S}\right)$ and headway distance $\left(D_{S}\right)$ of following vehicle before the lead vehicle's brake onset were sampled from experiment data and followed the normal distribution as $V_{F S} \sim N(16.78,2.00)$ and $D_{S} \sim N(27.98,10.43)$, respectively. Additionally, the critical distance $\left(D_{c}\right)$ which was used to define a rear-end collision occurrence between the lead and following vehicles is assumed to be $4 \mathrm{~m}$ (the headway distance was measured between the center points of the lead and following vehicle), which means that a rear-end collision occurs if the headway distance is less than $4 \mathrm{~m}$.

The Monte Carlo simulation was operated with 10000 simulation replications and the distributions of key variables were generated. Comparing the Monte Carlo simulation results with the driving simulator test results (as shown in Table 4), it is found that all the variables' distributions were quite close to the driving simulator results. Figure 8 shows the distribution of these key variables achieved by Monte Carlo simulation. Figure 9 illustrates the distribution of driving speed during the rear-end collision avoidance. The black solid line, green line, and red line represent the mean, upper bound, and lower bound of the following vehicle's speed, respectively. It can be found that drivers whose driving speed reduced more rapidly seem to react faster to the lead vehicle's speed reduction. Figure 10 illustrates the deceleration rate of the following vehicle with upper bound and lower bound. Correspondingly, drivers who react faster to the sudden brake of the lead vehicle tend to take a larger deceleration rate.

In order to investigate the influence of driving speed and headway distance on the rear-end collision risk, the Monte Carlo simulation was also operated based on the initial speed of following vehicle with five levels of $14 \mathrm{~m} / \mathrm{s}, 16 \mathrm{~m} / \mathrm{s}, 18$ $\mathrm{m} / \mathrm{s}, 20 \mathrm{~m} / \mathrm{s}$, and $22 \mathrm{~m} / \mathrm{s}$ and the headway distance with four levels of $15 \mathrm{~m}, 20 \mathrm{~m}, 25 \mathrm{~m}$, and $30 \mathrm{~m}$, respectively. The risk of rear-end collision was represented by the number of collisions during the 10000 simulation replications. Table 5 and Figure 11 show the simulated distribution of headway distance and the number of collisions. According to the simulation results, more collisions occur with the headway distance being $15 \mathrm{~m}$. For example, when the following vehicle's initial speed is $14 \mathrm{~m} / \mathrm{s}$ and $16 \mathrm{~m} / \mathrm{s}$, no collisions occur; when the following vehicle's initial speed increases to $18 \mathrm{~m} / \mathrm{s}$, the number of collisions increases to 3717 . When the following 
TABLE 3: Distributions of regression parameters with a $95 \%$ confidence interval for determining $t_{r}, t_{1}$, and $a_{m}$.

\begin{tabular}{ccccccc}
\hline \multicolumn{5}{c}{ Distribution of regression parameters } \\
\hline$t_{r}$ & $m_{1}$ & $m_{2}$ & $m_{3}$ & $m_{4}$ & $m_{5}$ & $m_{6}$ \\
& $N(-.061, .014)$ & - & - & $N(-.034, .005)$ & $N(.023, .002)$ & $N(1.327, .090)$ \\
$t_{1}$ & $n_{1}$ & $n_{2}$ & $n_{3}$ & $n_{4}$ & $n_{5}$ & $n_{6}$ \\
& - & $N(.071, .008)$ & $N(-.070, .007)$ & - & $N(.017, .003)$ & $u_{5}$ \\
$a_{m}$ & $u_{1}$ & $u_{2}$ & $u_{3}$ & $u_{4}$ & $N(.451, .081)$ \\
& $N(.244, .065)$ & $N(.212, .052)$ & $N(-.216, .027)$ & $N(.098, .049)$ & $u_{6}$ & $N(3.636, .318)$ \\
\hline
\end{tabular}

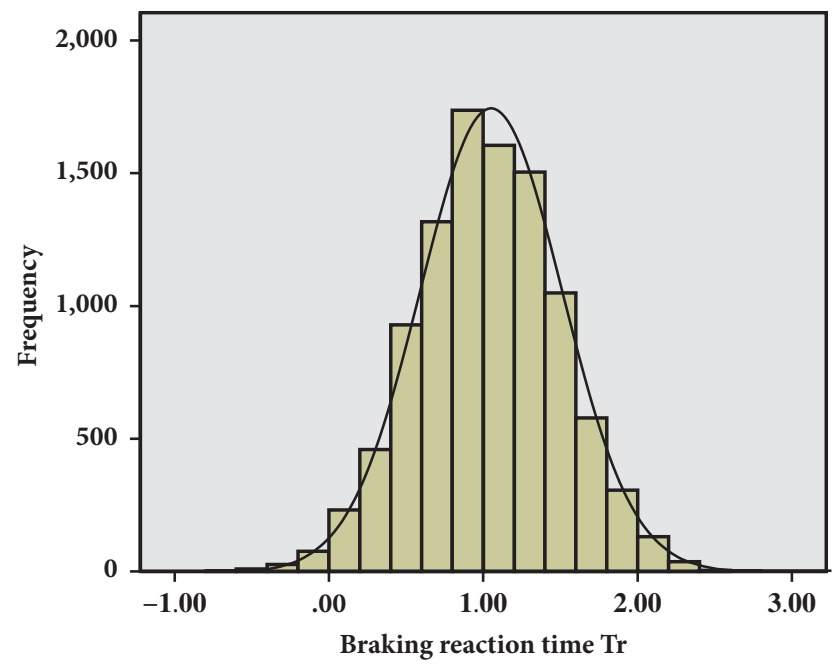

(a)

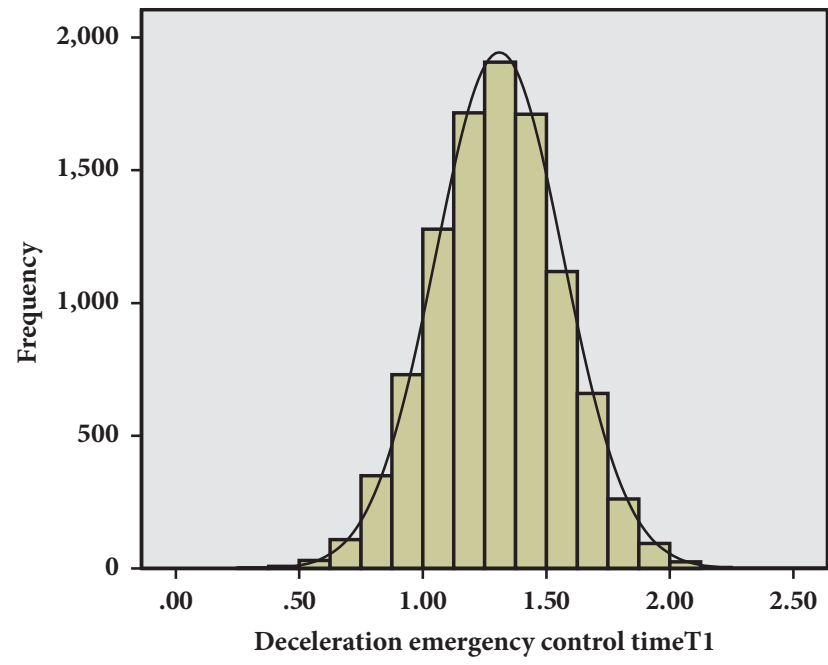

(b)

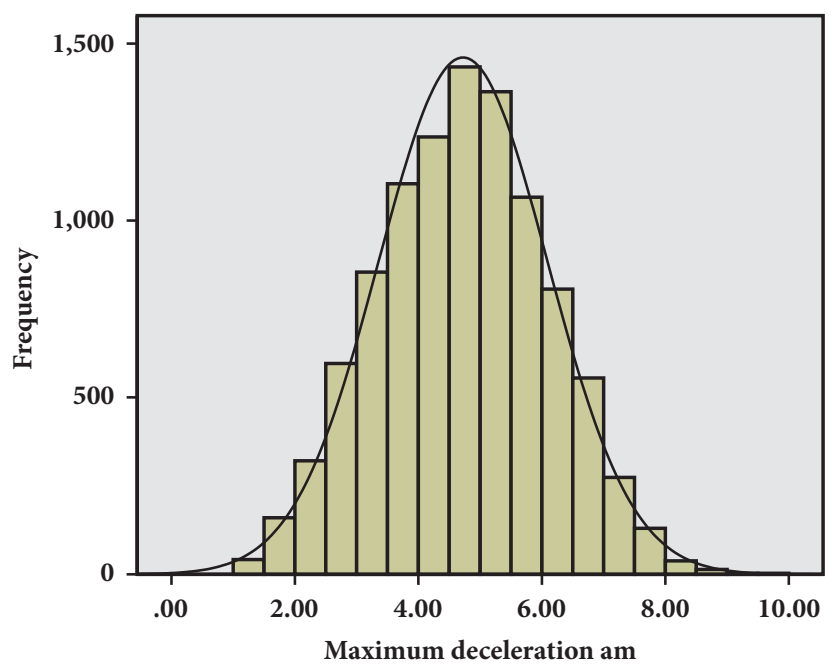

(c)

FIGURE 8: Distribution results of the key variables, braking response time (a), deceleration emergency control time (b), and drivers' maximum deceleration rate $(\mathrm{c})$, respectively.

TABLE 4: Comparison results of Monte Carlo simulation and driving simulator.

\begin{tabular}{lcccc}
\hline \multirow{2}{*}{ Variable } & \multicolumn{2}{c}{ Driving simulation data } & \multicolumn{2}{c}{ Monte-Carlo simulation } \\
\hline$t_{r}$ & Mean & S.D. & Mean & S.D. \\
$t_{1}$ & 1.10 & 0.48 & 1.16 & 0.15 \\
$a_{m}$ & 1.37 & 0.64 & 1.33 & 0.19 \\
\hline
\end{tabular}


TABLE 5: The Monte Carlo simulation results under different headway distances and initial speeds.

\begin{tabular}{|c|c|c|c|c|c|c|c|c|}
\hline \multirow{2}{*}{ Grade } & \multicolumn{2}{|c|}{$15 \mathrm{~m}(11 \mathrm{~m})$} & \multicolumn{2}{|c|}{$20 \mathrm{~m}(16 \mathrm{~m})$} & \multicolumn{2}{|c|}{$25 \mathrm{~m}(21 \mathrm{~m})$} & \multicolumn{2}{|c|}{$30 \mathrm{~m}(26 \mathrm{~m})$} \\
\hline & $\mathrm{D}$ & No. & $\mathrm{D}$ & No. & $\mathrm{D}$ & No. & $\mathrm{D}$ & No. \\
\hline $14 \mathrm{~m} / \mathrm{s}$ & $\mathrm{N}(14.75$ 1.08) & 0 & N (19.72 1.11) & 0 & $\mathrm{~N}(24.701 .14)$ & 0 & N (29.65 1.19) & 0 \\
\hline $16 \mathrm{~m} / \mathrm{s}$ & $\mathrm{N}(10.24$ 1.46) & 0 & $\mathrm{~N}(15.101 .52)$ & 0 & N (19.98 1.61) & 0 & $\mathrm{~N}(24.841 .64)$ & 0 \\
\hline $18 \mathrm{~m} / \mathrm{s}$ & $\mathrm{N}(5.251 .38)$ & 3717 & $\mathrm{~N}(9.991 .48)$ & 0 & $\mathrm{~N}(14.721 .52)$ & 0 & N (19.48 1.59) & 0 \\
\hline $20 \mathrm{~m} / \mathrm{s}$ & $\mathrm{N}(3.690 .24)$ & 9979 & $\mathrm{~N}(5.351 .38)$ & 3257 & N (9.93 1.57) & 0 & $\mathrm{~N}(14.641 .58)$ & 0 \\
\hline $22 \mathrm{~m} / \mathrm{s}$ & $\mathrm{N}(3.690 .11)$ & 10000 & $\mathrm{~N}\left(\begin{array}{lll}3.71 & 0.29\end{array}\right)$ & 9856 & $\mathrm{~N}(5.621 .56)$ & 2876 & $\mathrm{~N}(10.14$ 1.75) & 6 \\
\hline
\end{tabular}

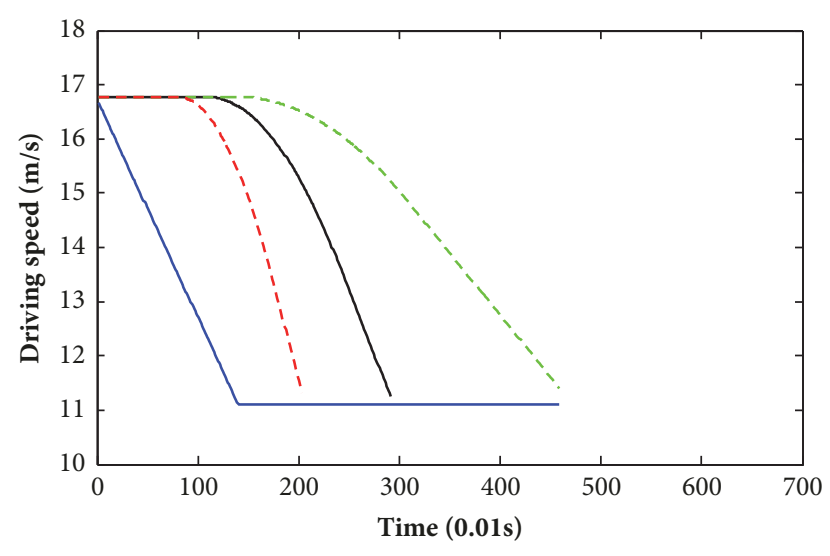

- Speed of leading vehicle
- Average speed of following vehicle
- - - Upper bound speed of following vehicle
- - - Lower bound speed of following vehicle

FIGURE 9: The distribution of driving speed (with a 95\% confidence interval).

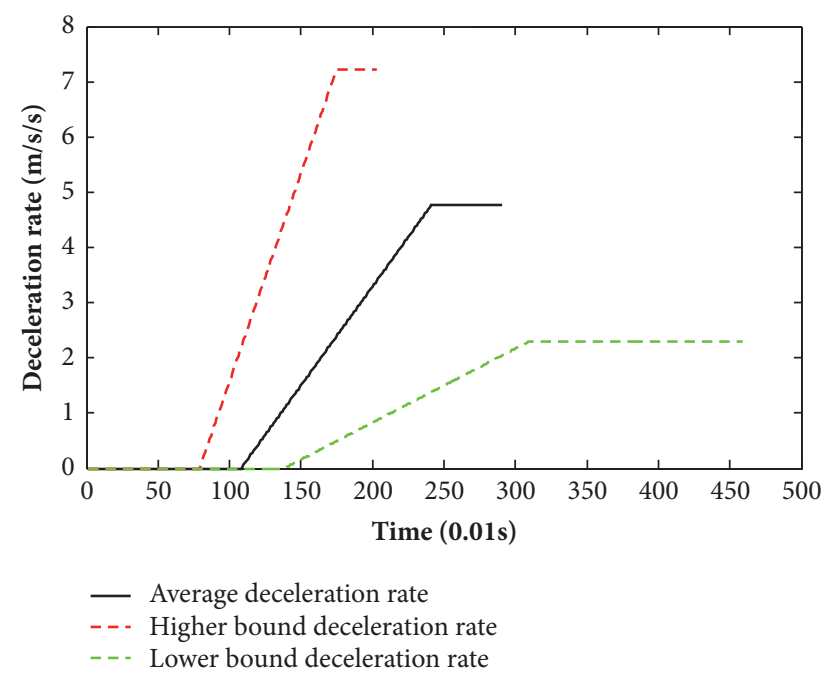

FIGURE 10: The distribution of deceleration rate (with a $95 \%$ confidence interval).

vehicle's initial speed exceeds $18 \mathrm{~m} / \mathrm{s}$, the probability of rearend collision reaches $100 \%$. However, when the headway distance is $20 \mathrm{~m}$, no collisions occur with the following vehicle's initial speed less than $18 \mathrm{~m} / \mathrm{s}$. More collisions occur when the following vehicle's speed is $20 \mathrm{~m} / \mathrm{s}$ and $22 \mathrm{~m} / \mathrm{s}$
(3257 and 9856, respectively). With the headway distance continuing to increase, collisions reduce to zero with the initial driving speed being $20 \mathrm{~m} / \mathrm{s}$. When the headway distance increases to $30 \mathrm{~m}$, only six collisions occur with the initial following speed being $22 \mathrm{~m} / \mathrm{s}$. Studies conducted in both a field study [49] and a driving simulator study [50] had shown that the headway distance between vehicles was longer at a higher driving speed. Thus when driving speed continues to increase while the headway still keeps the same distance, it may be difficult for drivers to make a timely response to avoid a rear-end collision with the lead vehicle. Another interesting result is that, with the same initial following speed, $18 \mathrm{~m} / \mathrm{s}$, for example, the number of collisions reduced from 3717 to zero when headway distance increased from $15 \mathrm{~m}$ to $20 \mathrm{~m}$. According to the previous studies [51, 52], the mean time headway to keep safe was about 1-2 s. Thus a safety distance may be reached between $15 \mathrm{~m}$ and $20 \mathrm{~m}$, and once the initial headway distance in this simulation surpassed the safety distance, the collisions reduced significantly.

\section{Conclusions}

The present study developed a rear-end avoidance behaviour model considering drivers' individual differences during the car-following and collision avoidance process, filling the gap of most previous studies that ignored driver heterogeneity. The most significant difference was that the key variables in the collision avoidance such as reaction time and maximum deceleration were input into the model as distribution form instead of constant value. A Monte Carlo method was applied in the model simulation. The simulation results verified the effectiveness of the model and further examined the influence of driving speed and headway distance on the rear-end collision risk. As the major role of distance to avoid rearend crash has been verified by numerous studies [53,54], this study investigated its combined effect with driving speed and further found that, on one hand, when the headway distance kept by following vehicle fell below $15 \mathrm{~m}$, the probability of rear-end collisions increased significantly with driving speed continuing to grow. On the other hand, when the driving speed was small, the collision risk was not significantly different with different distance distribution. However, as the driving speed exceeded $18 \mathrm{~m} / \mathrm{s}$, the risk of rear-end crash grew rapidly with the decrease of headway distance. As Hamdar [25] and Treiber and Kesting [26] presented, human factors included many aspects. External performance was generally accompanied by internal motivations. Thus, future studies will focus on drivers' eye movement in the car-following 

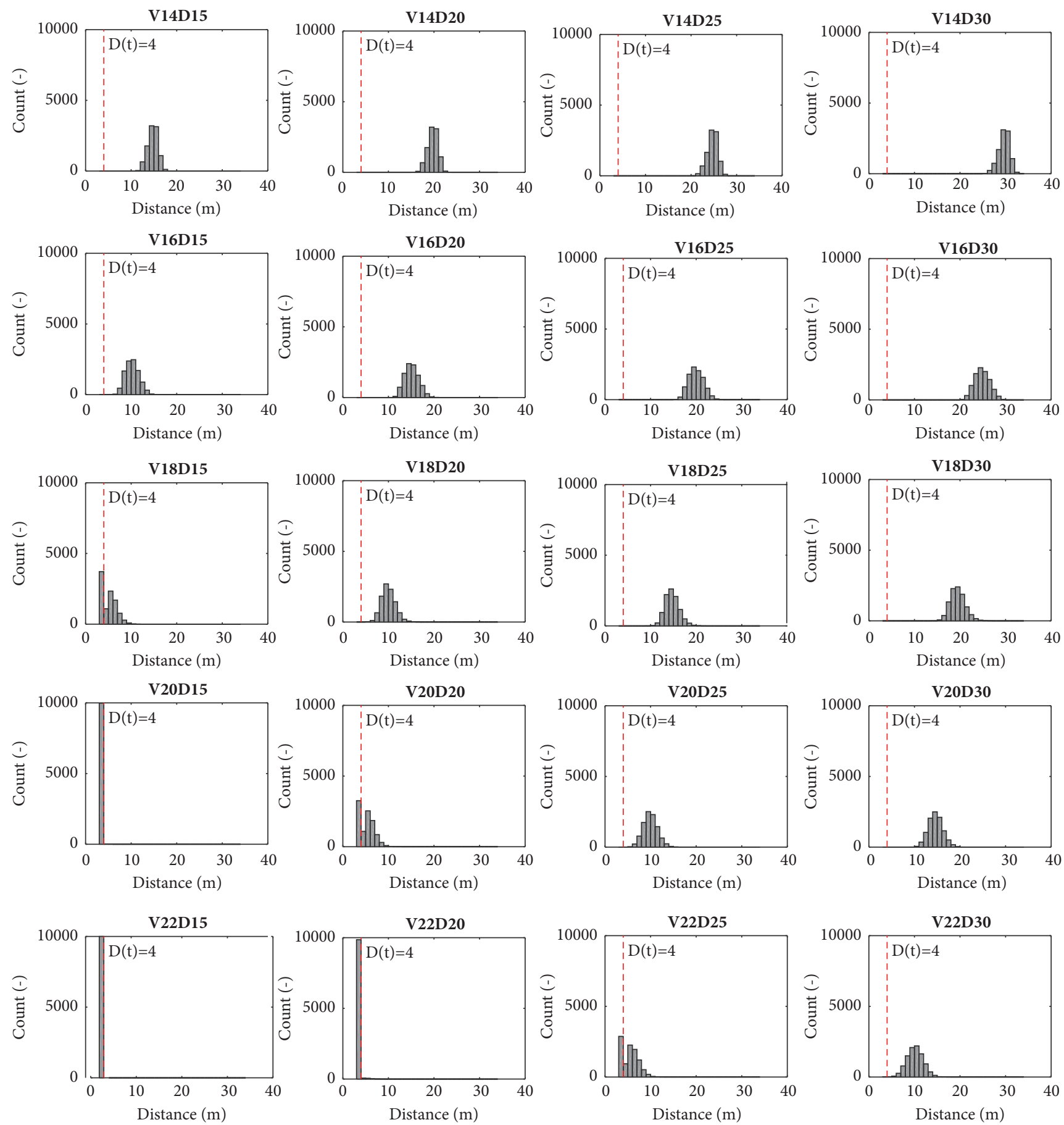

FIGURE 11: The probability of rear-end collisions under five levels of speed and four levels of distance conditions (V represents driving speed and D represents headway distance; e.g., V14D15 means the driving speed is $14 \mathrm{~m} / \mathrm{s}$ and headway distance is $15 \mathrm{~m}$ ).

process with data collected by eye tracker, which may provide a better understanding of the cognitive process in the rearend collision avoidance.

\section{Data Availability}

The data used to support the findings of this study are available from the corresponding author upon request.

\section{Conflicts of Interest}

The authors declare no conflicts of interest.

\section{Acknowledgments}

This work is financially supported by the National Natural Science Foundation of China (71771014, 71621001). 


\section{References}

[1] World Health Organization, "Global status report on road safety: supporting a decade of action,” 2013.

[2] National Highway Traffic Safety Administration, Analyses of Rear-End Crashes and Near-Crashes in the100-Car Naturalistic Driving Study to Support Rear-Signaling Countermeasure Development, Springfield, Fairfax, VA, USA, 2007.

[3] Highway safety manual 2009.

[4] M. Brackstone and M. McDonald, "Car-following: a historical review," Transportation Research Part F: Traffic Psychology and Behaviour, vol. 2, no. 4, pp. 181-196, 1999.

[5] M. Saifuzzaman and Z. Zheng, "Incorporating human-factors in car-following models: a review of recent developments and research needs," Transportation Research Part C: Emerging Technologies, vol. 48, pp. 379-403, 2014.

[6] D. C. Gazis, R. Herman, and R. W. Rothery, "Nonlinear followthe-leader models of traffic flow," Operations Research, vol. 9, no. 4, pp. 545-567, 1961.

[7] E. Kometani and T. Sasaki, "Dynamic behaviour of traffic with a non-linear spacing-speed relationship," in Proceedings of the Symposium on Theory of Traffic Flow, Research Laboratories, General Motors, Elsevier, New York, NY, USA, 1959.

[8] P. G. Gipps, "A behavioural car-following model for computer simulation," Transportation Research Part B: Methodological, vol. 15, no. 2, pp. 105-111, 1981.

[9] M. Bando, K. Hasebe, A. Nakayama, A. Shibata, and Y. Sugiyama, "Dynamical model of traffic congestion and numerical simulation," Physical Review E: Statistical, Nonlinear, and Soft Matter Physics, vol. 51, no. 2, pp. 1035-1042, 1995.

[10] F. Sun, J. Wang, R. Cheng, and H. Ge, "An extended heterogeneous car-following model accounting for anticipation driving behavior and mixed maximum speeds," Physics Letters A, vol. 382, no. 7, pp. 489-498, 2018.

[11] S. Yu and Z. Shi, "An extended car-following model considering vehicular gap fluctuation," Measurement, vol. 70, pp. 137-147, 2015.

[12] S. Yu and Z. Shi, "An improved car-following model considering headway changes with memory," Physica A: Statistical Mechanics and its Applications, vol. 421, pp. 1-14, 2015.

[13] D. Helbing and B. Tilch, "Generalized force model of traffic dynamics," Physical Review E: Statistical, Nonlinear, and Soft Matter Physics, vol. 58, no. 1, pp. 133-138, 1998.

[14] S. Yu, J. Tang, and Q. Xin, "Relative velocity difference model for the car-following theory," Nonlinear Dynamics, vol. 91, no. 3, pp. 1415-1428, 2018.

[15] S. Yu and Z. Shi, "An improved car-following model considering relative velocity fluctuation," Communications in Nonlinear Science and Numerical Simulation, vol. 36, pp. 319-326, 2016.

[16] R. Jiang, Q. Wu, and Z. Zhu, "Full velocity difference model for a car-following theory," Physical Review E: Statistical, Nonlinear, and Soft Matter Physics, vol. 64, no. 1, Article ID 017101, 2001.

[17] G. Zhang, D.-H. Sun, M. Zhao, X.-Y. Liao, W.-N. Liu, and T. Zhou, "An extended car-following model accounting for cooperation driving system with velocity uncertainty," Physica A: Statistical Mechanics and its Applications, vol. 505, pp. 1008-1017, 2018.

[18] R. Michaels, "Perceptual factors in car following," in Proceedings of the 2nd International Symposium on the Theory of Road Traffic Flow, OECD, Organisation for economic co-operation and development, London, UK, 1963.
[19] G. J. Andersen and C. W. Sauer, "Optical information for car following: The driving by visual angle (DVA) model," Human Factors: The Journal of the Human Factors and Ergonomics Society, vol. 49, no. 5, pp. 878-896, 2007.

[20] J. Zhou, "An extended visual angle model for car-following theory," Nonlinear Dynamics, vol. 81, no. 1-2, pp. 549-560, 2015.

[21] P.-G. Hou, H.-W. Yu, C. Yan, and J.-Y. Hong, "An extended carfollowing model based on visual angle and backward looking effect," Chinese Journal of Physics, vol. 55, no. 5, pp. 2092-2099, 2017.

[22] R. Michaels and L. Cozan, "Perceptual and field factors causing lateral displacement," Highway Research Record, vol. 25, pp. 1-13, 1963.

[23] P. Ferrari, "The effect of driver behaviour on motorway reliability," Transportation Research Part B: Methodological, vol. 23, no. 2, pp. 139-150, 1989.

[24] E. R. Hoffmann and R. G. Mortimer, "Scaling of relative velocity between vehicles," Accident Analysis \& Prevention, vol. 28, no. 4, pp. 415-421, 1996.

[25] Z. Papp, "Situational awareness in intelligent vehicles," in Handbook of Intelligent Vehicles, A. Eskandarian, Ed., pp. 62-78, Springer, 2012.

[26] M. Treiber and A. Kesting, Traffic Flow Dynamics: Data, Models and Simulation, Springer, Berlin, Germany, 2013.

[27] J.-B. Sheu and H.-J. Wu, "Driver perception uncertainty in perceived relative speed and reaction time in car following - A quantum optical flow perspective," Transportation Research Part B: Methodological, vol. 80, pp. 257-274, 2015.

[28] I. Kim, T. Kim, and K. Sohn, "Identifying driver heterogeneity in car-following based on a random coefficient model," Transportation Research Part C: Emerging Technologies, vol. 36, pp. 34-44, 2013.

[29] I. Yamada and J.-C. Thill, "Comparison of planar and network K-functions in traffic accident analysis," Journal of Transport Geography, vol. 12, no. 2, pp. 149-158, 2004.

[30] W. Chen, C. Yang, F. Feng, and Z. Chen, "An improved model for headway-based bus service unreliability prevention with vehicle load capacity constraint at bus stops," Discrete Dynamics in Nature and Society, vol. 2012, 2012.

[31] A. Sumalee, R. X. Zhong, T. L. Pan, and W. Y. Szeto, "Stochastic cell transmission model (SCTM): a stochastic dynamic traffic model for traffic state surveillance and assignment," Transportation Research Part B: Methodological, vol. 45, no. 3, pp. 507-533, 2011.

[32] S. Liu, Z. Song, and S. Zhong, "Public transportation hub location with stochastic demand: an improved approach based on multiple attribute group decision-making," Discrete Dynamics in Nature and Society, vol. 2015, Article ID 430109, 15 pages, 2015.

[33] H. A. P. Blom, G. J. Bakker, P. J. G. Blanker, J. Daams, M. H. C. Everdij, and M. B. Klompstra, "Accident risk assessment for advanced air traffic management," Air Transportation Systems Engineering Aiaa, pp. 463-480, 2001.

[34] M. H. Everdij, M. B. Klompstra, H. A. Blom, and B. Klein Obbink, "Compositional specification of a multi-agent system by stochastically and dynamically coloured Petri nets," in Stochastic hybrid systems, vol. 337 of Lect. Notes Control Inf. Sci., pp. 325-350, Springer, Berlin, 2006.

[35] S. H. Stroeve, H. A. P. Blom, and G. J. (Bert) Bakker, "Systemic accident risk assessment in air traffic by Monte Carlo simulation," Safety Science, vol. 47, no. 2, pp. 238-249, 2009. 
[36] C. Gibbons, N. Mullen, B. Weaver, P. Reguly, and M. Bédard, "One-And three-screen driving simulator approaches to evaluate driving capacity: evidence of congruence and participants' endorsement," American Journal of Occupational Therapy, vol. 68, no. 3, pp. 344-352, 2014.

[37] M. Bédard, M. Parkkari, B. Weaver, J. Riendeau, and M. Dahlquist, "Assessment of driving performance using a simulator protocol: validity and reproducibility," The American Journal of Occupational Therapy, vol. 64, no. 2, pp. 336-340, 2010.

[38] X. Wang, M. Zhu, M. Chen, and P. Tremont, "Drivers' rear end collision avoidance behaviors under different levels of situational urgency," Transportation Research Part C: Emerging Technologies, vol. 71, pp. 419-433, 2016.

[39] E. Muhrer and M. Vollrath, "Expectations while car followingthe consequences for driving behaviour in a simulated driving task," Accident Analysis \& Prevention, vol. 42, no. 6, pp. 21582164, 2010.

[40] F. Bella and R. Russo, "A collision warning system for rearend collision: A driving simulator study," Procedia Social and Behavioural Sciences, vol. 20, pp. 676-686, 2011.

[41] X. Li, X. Yan, J. Wu, E. Radwan, and Y. Zhang, "A rear-end collision risk assessment model based on drivers' collision avoidance process under influences of cell phone use and gender-A driving simulator based study," Accident Analysis \& Prevention, vol. 97, pp. 1-18, 2016.

[42] R. F. Sanches, A. M. P. De Jesus, J. A. F. O. Correia, A. L. L. Da Silva, and A. A. Fernandes, "A probabilistic fatigue approach for riveted joints using Monte Carlo simulation," Journal of Constructional Steel Research, vol. 110, pp. 149-162, 2015.

[43] U. Arnold and Ö. Yildiz, "Economic risk analysis of decentralized renewable energy infrastructures - A Monte Carlo Simulation approach," Journal of Renewable Energy, vol. 77, no. 1, pp. 227-239, 2015.

[44] B. Amigun, D. Petrie, and J. Gorgens, "Economic risk assessment of advanced process technologies for bioethanol production in South Africa: Monte Carlo analysis," Journal of Renewable Energy, vol. 36, no. 11, pp. 3178-3186, 2011.

[45] Y. Xi, H. Peng, and Y. Qin, "Modeling financial time series based on a market microstructure model with leverage effect," Discrete Dynamics in Nature and Society, Art. ID 1580941, 15 pages, 2016.

[46] W. Wach and J. Unarski, "Uncertainty of calculation results in vehicle collision analysis," Forensic Science International, vol. 167, no. 2-3, pp. 181-188, 2007.

[47] K. Vogel, "A comparison of headway and time to collision as safety indicators," Accident Analysis \& Prevention, vol. 35, no. 3, pp. 427-433, 2003.

[48] A. Kolasa-Wiecek, "Stepwise multiple regression method of greenhouse gas emission modeling in the energy sector in Poland," Journal of Environmental Sciences, vol. 30, pp. 47-54, 2015.

[49] M. Taieb-Maimon and D. Shinar, "Minimum and comfortable driving headways: Reality versus perception," Human Factors: The Journal of the Human Factors and Ergonomics Society, vol. 43, no. 1, pp. 159-172, 2001.

[50] J. Duan, Z. Li, and G. Salvendy, "Risk illusions in car following: Is a smaller headway always perceived as more dangerous?" Safety Science, vol. 53, pp. 25-33, 2013.

[51] C. J. Colbourn, I. D. Brown, and A. K. Copeman, "Drivers' Judgments of Safe Distances in Vehicle Following," Human Factors: The Journal of Human Factors and Ergonomics Society, vol. 20, no. 1, pp. 1-11, 1978.
[52] P. Wasielewski, "Car following headways on freeways interpreted by the semi-Poisson headway distribution model," Transportation Science, vol. 13, no. 1, pp. 36-55, 1979.

[53] L. Evans and P. Wasielewski, "Do accident-involved drivers exhibit riskier everyday driving behavior?" Accident Analysis \& Prevention, vol. 14, no. 1, pp. 57-64, 1982.

[54] M. Brackstone, B. Sultan, and M. McDonald, "Motorway driver behaviour: Studies on car following," Transportation Research Part F: Traffic Psychology and Behaviour, vol. 5, no. 1, pp. 329344, 2002. 


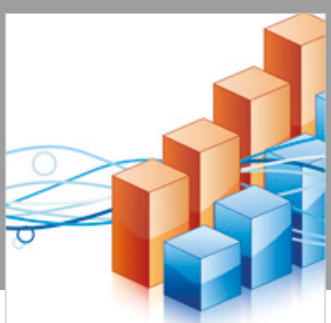

Advances in

Operations Research

\section{-n-m}
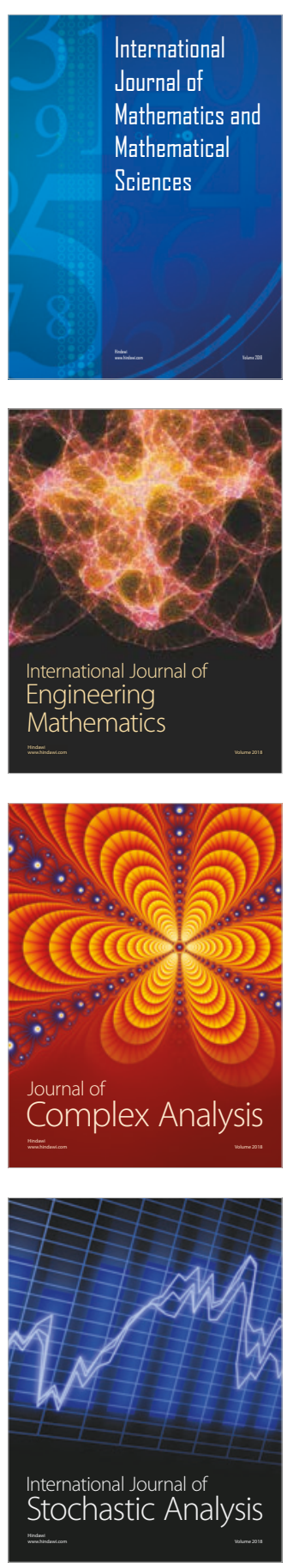
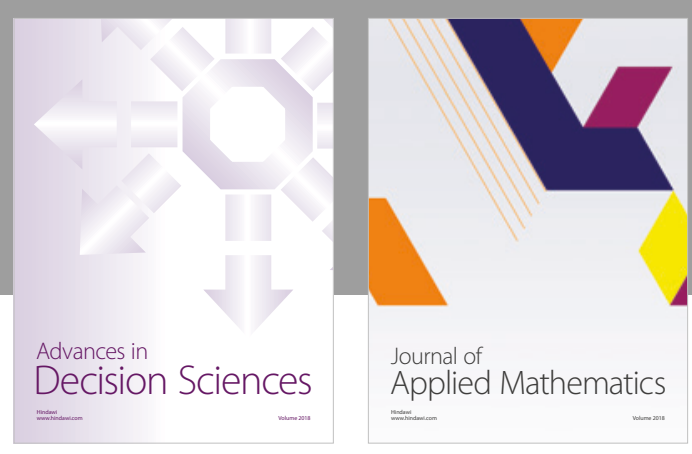

Journal of

Applied Mathematics
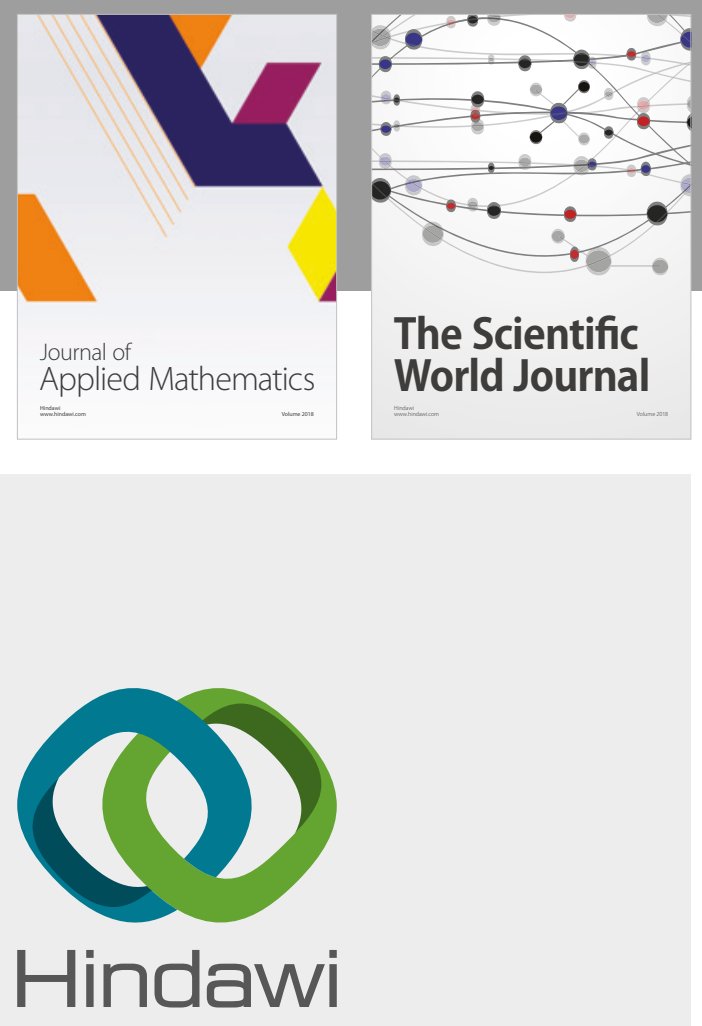

Submit your manuscripts at

www.hindawi.com

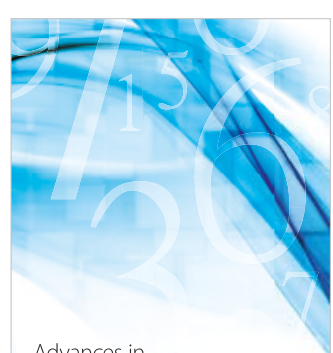

Advances in
Numerical Analysis
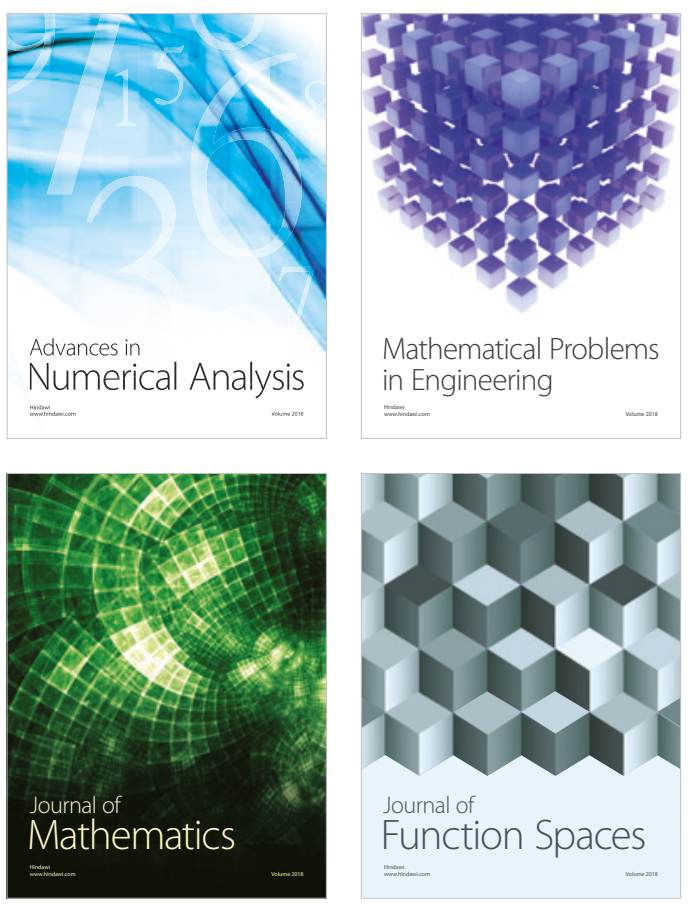

Mathematical Problems in Engineering

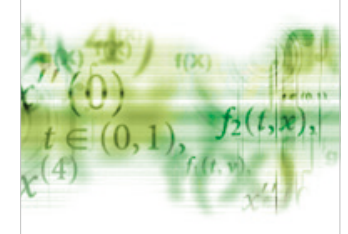

International Journal of

Differential Equations

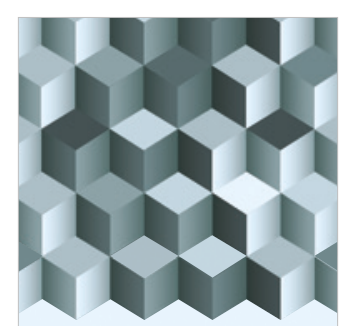

Journal of

Function Spaces

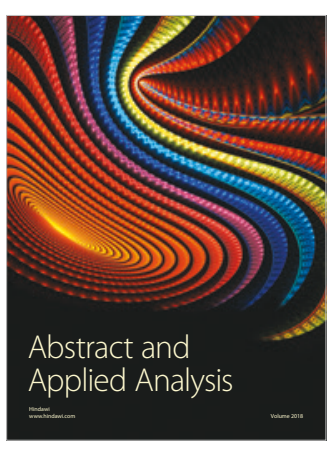

The Scientific

World Journal

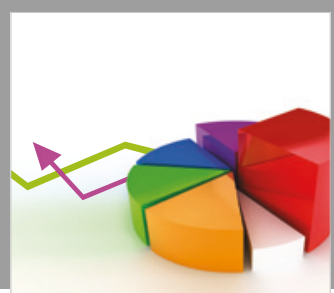

Journal of

Probability and Statistics
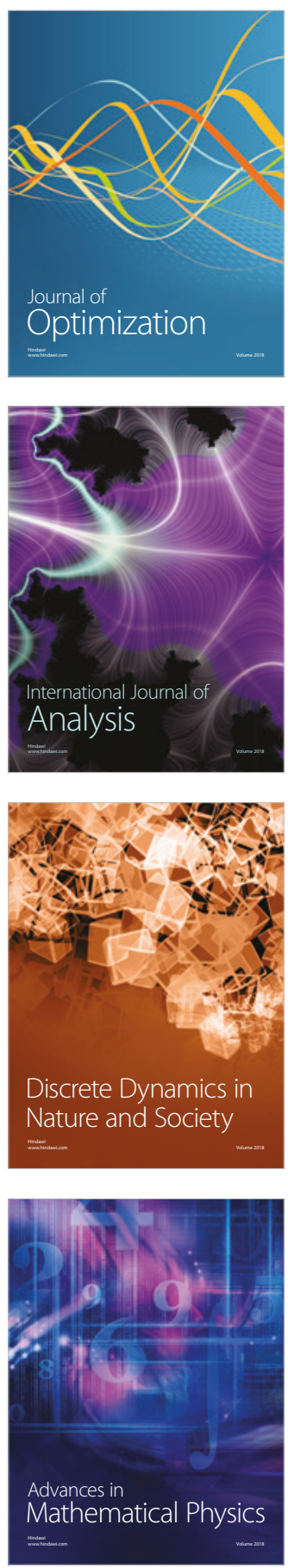